\title{
Belgian case study on flumethrin residues in beeswax: Possible impact on honeybee and prediction of the maximum daily intake for consumers
}

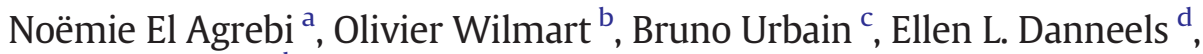 \\ Dirk C. de Graaf ${ }^{\mathrm{d}, \mathrm{e}}$, Claude Saegerman ${ }^{\mathrm{a}}{ }{ }_{*}$
}

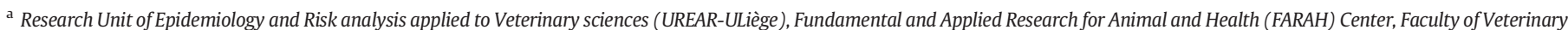
Medicine, University of Liège, Quartier Vallée 2, Avenue de Cureghem 7A, B42, 4000 Liège, (Sart-Tilman), Belgium

${ }^{\mathrm{b}}$ Federal Agency for the Safety of the Food Chain (FASFC), Directorate Control Policy, Staff Direction for Risk Assessment, Boulevard du Jardin Botanique 55, 1000 Brussels, Belgium

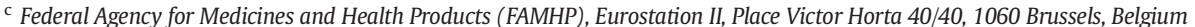

d Faculty of Sciences, Honeybee Valley, Ghent University (UGent), Krijgslaan 281 S33, 9000 Ghent, Belgium

e Faculty of Sciences, Laboratory of Molecular Entomology and Bee Pathology, Ghent University (UGent), Krijgslaan 281 S2, 9000 Ghent, Belgium

\section{H I G H L I G H T S}

- Study of flumethrin presence in beeswax and its risk to bees and human health

- Mean Flumethrin prevalence rate in beeswax was of $21.77 \%$ (95\% CI: 14.87-30.08).

- Oral hazard quotient is above recommended threshold representing a risk to bees.

- No relation was established between flumethrin in beeswax and bee mortality.

- Flumethrin residues in beeswax and in honey do not pose a risk to human health.

\section{G R A P H I C A L A B S T R A C T}

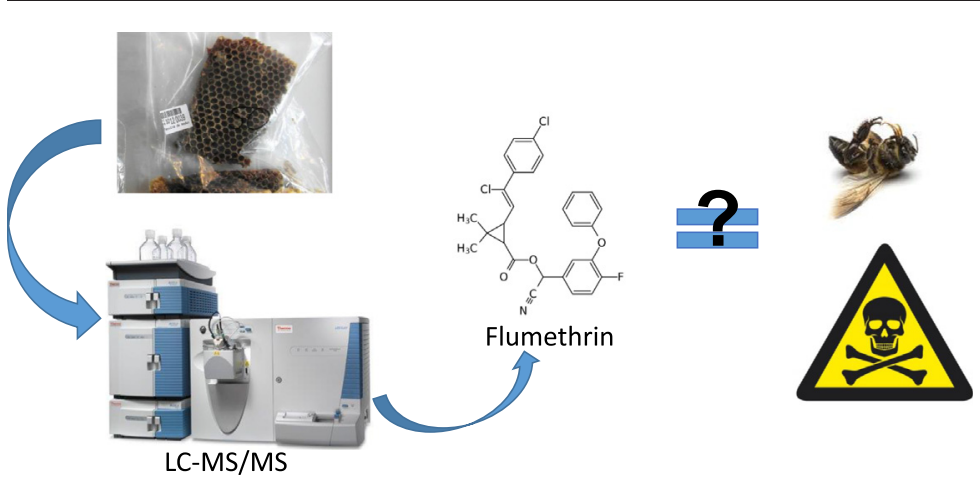

\begin{abstract}
A B S T R A C T
To assess the health risk posed by flumethrin residues in beeswax to honeybees and honey consumers, 124 wax samples randomly distributed in Belgium were analysed for flumethrin residues using liquid chromatography/tandem mass spectrometry. The risk posed by flumethrin residues in beeswax to honeybee health was assessed through the calculation of a non-pondered and a pondered Hazard Quotient by the prevalence rate of flumethrin considering an oral or topical exposure. No statistical difference was found when comparing both the average flumethrin residues concentrations and contact and oral pondered hazard quotients between apiaries with lower and equal or higher than $10 \%$ of colony loss. Flumethrin residues estimated daily intake by Belgian consumers through honey and wax ingestion was estimated via a deterministic (worst-case scenario) and a probabilistic approach. The probabilistic approach was not possible for beeswax consumption due to the lack of individual consumption data.
\end{abstract}

Keywords:

Risk assessment

Pyrethroid

Apis mellifera

Veterinary substance

Abbreviations: ADI, acceptable daily intake; bw, body weight; df, degree of freedom; EDC, estimated daily contribution; EDI, estimated daily intake; FASFC, Federal Agency for the Safety

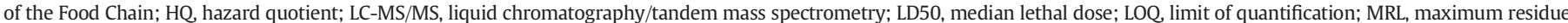
limit; QuEChERS, quick, easy, cheap, effective, rugged, and safe; S.D., standard deviation; TMDI, theoretical maximum daily intake; VSDB, Veterinary Substances Data Base.

* Corresponding author.

E-mail address: claude.saegerman@uliege.be (C. Saegerman). 
Consumer

Food safety
The highest estimated exposure was $<0.1 \%$ of the theoretical maximum daily intake for both approaches, meaning no risk for human health.

\section{Introduction}

Honeybee health and mortality are of concern (Aizen et al., 2009; Fontaine et al., 2005; Garibaldi et al., 2014; Klein et al., 2007; Pettis et al., 2012; Potts et al., 2010; Sanchez-Bayo and Goka, 2014) in North America as well as in Europe, and particularly in Belgium. Honeybee colony development success depends partly on the management of the ectoparasitic bee mite Varroa destructor, which has historically been treated using varroacides that may also impact honeybee health (Johnson et al., 2013). Many studies have pointed out pesticides as one of the main stressors affecting colony development/survival (e.g. Balbuena et al., 2015; Johnson et al., 2013; Rumkee et al., 2015). Honeybee exposure to pesticides may result in adverse health impacts such as acute and chronic mortality or sub-lethal effects (Chauzat et al., 2009; EFSA, 2012; Hardstone and Scott, 2010). Understanding and quantifying the risks of pesticides entering the hive is challenging as pesticide risk is currently determined via short-term acute contact and oral toxicity tests on adult bees (i.e., $\mathrm{LD}_{50}$ ), which avoid synergistic, cumulative, sublethal effects on the colony (Traynor et al., 2016) and which do not take the possible toxicokinetic profile of bees into account (Hesketh et al., 2016). Honeybee chronic toxicity tests over 10 days are suggested by the OECD (OECD, 2018), as well as the standardized chronic toxicity tests for larvae (OECD, 2013).

Flumethrin is a synthetic pyrethroid ectoparasiticide commonly used in veterinary medicine and one of the varroacides used for the control and treatment of Varroa mites in beekeeping (Johnson, 2014; Oruc et al., 2012). In beekeeping, strips impregnated with $3.6 \mathrm{mg}$ of the active substance flumethrin are suspended into the space between the combs in the central brood rearing area for several weeks; normally developed colonies receive four strips per brood chamber (EMEA, 1998). Flumethrin belongs to group 1, highly toxic to honeybees pesticides, from the pyrethroids class of synthetic insecticides, based on the structure and insecticidal activity of the pyrethrins, with a broad range of toxicity to adult bees (Oruc et al., 2012). Flumethrin acute oral $\mathrm{DL}_{50}$ is $0.178 \mu \mathrm{g} /$ bee (Oruc et al., 2012) and its contact $\mathrm{DL}_{50}$ is $0.05 \mu \mathrm{g} / \mathrm{bee}$ (Perez Santiago et al., 2000). Flumethrin affects the insect nervous system by causing multiple action potentials in the nerve cells, by delaying the closing of ion channels (Oruc et al., 2012). In addition of being highly toxic to adult bees (Oruc et al., 2012), applying varroacides in honeybee colonies leaves residues in bee products, especially in beeswax. Varroacides accumulate in beeswax with years of treatments, reaching such high concentration levels up to the $\mathrm{mg} \mathrm{kg}^{-1}$ (Lozano et al., 2019), given that they are mostly fat-soluble, non-volatile (Wilmart et al., 2016) and given that old comb beeswax is recycled continuously into new foundations (Ravoet et al., 2015; Tlak Gajger et al., 2016). Beeswax is primarily used in beekeeping to produce comb foundations but also in the chemical, cosmetic, pharmaceutical and food industries. Beeswax is a natural wax produced by the worker bees in their wax-producing mirror glands on the inner sides of the sternites on abdominal segments (Reybroeck et al., 2010). The new wax scales are masticated by the worker bees and used to build honeycomb cells in which brood is raised, and nectar and pollen are stored (Ravoet et al., 2015; Thompson, 2012). Ripened honey is also capped with wax (EFSA, 2007). Contact between beeswax and honey enables chemical transfer between these two matrices (Tremolada and Vighi, 2014). This carry-over could lead to an exceeding maximum residue limits, which could pose a health risk to consumers and honeybee health (Benuszak et al., 2017; Wilmart et al., 2016). Nevertheless, transfer of flumethrin from beeswax to honey has been estimated as negligible (EMEA, 1998; Karazafiris et al., 2012;
Wallner, 1999) as its octanol-water partition coefficient at pH 7 and $20^{\circ} \mathrm{C}$ (i.e. Log P) is 6.2 (Veterinary Substances Data Base, Pesticide Properties DataBase: http://sitem.herts.ac.uk/aeru/ppdb/en/atoz.htm), which corresponds to a highly lipophilic substance. At European level, the EU commission has set the average consumption of honey at $5 \mathrm{~g} /$ capita/day representing a very small part of the total diet (EU Commission, 2018). For Belgium, the value of $50 \mathrm{~g}$ honey per day and per person is recorded as the 95th percentile of the chronic daily consumption (consumers only) for an adult according to the EFSA Comprehensive European Food Consumption Database (Wilmart et al., 2016). In addition, in Belgium, the average consumption of $16.41 \mathrm{~g}$ honey per day and per person (honey consumers only) was recorded in consumers older than 14 years of both sex (De Vriese et al., 2005). Concerning beeswax, a consumption of $1.29 \mathrm{~g}$ beeswax per day and per person was calculated by the EFSA (EFSA, 2007). This conservative assumption is based on the 95th percentile of consumption of foodstuffs containing beeswax as they increase human exposure through secondary routes such as consumption of food additives, coating agents in pastry preparation, capsules and tablets, surface treatment of certain fruits (EFSA, 2007). The consumption of honey and beeswax only as foodstuffs were taken into account, not as cosmetics or pharmaceuticals. We considered the consumer as an adult of $60 \mathrm{~kg}$ body weight (bw) (Wilmart et al., 2016). Pyrethroids, including flumethrin, show almost negligible acute toxicity to humans but are highly toxic to target organism. The main effects of pyrethroids are neurotoxicity at high doses and liver hypertrophy, which are reversible if death does not occur. Symptoms of chronic toxicity of pyrethroids include memory loss, change in immunity system, behavioral problems, thyroid problem etc. (Patel and Patil, 2016).

In Belgium, until February 2017, flumethrin was only authorised under veterinary prescription using the "cascade system". The cascade system was introduced to solve the general problem of availability of veterinary medicinal products for minor species and for minor uses (Reybroeck et al., 2010). Until today, no maximum residue limit (MRL) due to the veterinary use of flumethrin is required in honey according to European Commission Regulation (EU, 2002), because the residue levels in honey were generally lower than the limit of detection (LOD) of the analytical method (1-2 $\mu \mathrm{g} / \mathrm{kg})$, and this while, at the same time, the concentration of flumethrin in the beeswax from the same treated hives amounted to $130 \mu \mathrm{g} / \mathrm{kg}$ (EMEA, 1998).

In February 2017, flumethrin veterinary medicine product obtained a European Marketing Authorisation (MA) in several EU member states, including Belgium. This product is commercialised under the name of PolyVar Yellow ${ }^{\circledR}$ ( $275 \mathrm{mg}$ bee hive strip containing holes). The strips should be fitted at the entrance in a way that the bees are forced to enter or leave the hive only through the holes of the strip.

The present unprecedented study was motivated by the high losses of honeybee colonies observed in Belgium last years. The objective of the study was to perform a flumethrin nationwide monitoring of comb wax in order to determine the prevalence rates and the contamination levels in Belgian apiaries. During the survey (beekeeping season 2016), beeswax samples were collected and honeybee mortality rates were registered (from May to October 2016). The novelty of this study was testing the possible relation between flumethrin residues concentrations and honeybee mortality as well as the assessment of the risk posed by flumethrin residues in beeswax to honeybees through contact or oral exposure (mastication). For this last purpose, the masticated wax quantity had to be beforehand estimated, as these quantities were not known. In addition, using both deterministic and probabilistic 
approaches, we estimated according to different scenarios the daily intake of flumethrin residues through consumption of beeswax and honey per day and per person and we compared it to the theoretical maximum daily intake (TMDI) estimated by EMEA (1998) as equal to $108 \mu \mathrm{g} /$ day.

\section{Materials and methods (including safety information)}

\subsection{Epidemiological unit of interest}

When applied to beekeeping, it is important to define the "epidemiological unit" for which the case definition is being applied. Epidemiological units are the groups which make up the population of interest, and can range from individual bees, colonies, and apiaries (van Engelsdorp et al., 2013). For this study, the epidemiological unit used to assess the risk for honeybee health is the individual adult honeybee, Nevertheless, larvae reared in cells are in closer contact with residues contained in the wax (Chauzat and Faucon, 2007) and are thus more at risk than bees. Unfortunately, the risk to larvae could not be assessed as we still lack acute and chronic, contact and oral toxicity tests (i.e., $\mathrm{LD}_{50}$ ) for larvae. To characterise honeybee mortality, the colony was considered as the unit of interest.

\subsection{Beeswax sampling}

One sample of $20 \mathrm{~g}$ of comb wax was withdrawn from 1 hive per apiary out of 124 apiaries, randomly selected and uniformly spread in each of the ten Belgian provinces (Fig. 1). Whenever possible, samples were collected from an area of used brood comb, out of the hive body, not containing any beebread, honey or brood (Traynor et al., 2016). The sampled bee colonies seemed healthy, with no clinical signs of infectious diseases or acute intoxication (Ravoet et al., 2015). Potential variations in climatic factors between different sampling locations were minimised by collecting beeswax matrices during the same beekeeping season, from May to October 2016. In Belgium, veterinary treatments against Varroa mite are applied typically two times a year: first around New Year (oxalic acid) in the absence of brood, then right after honey harvest (varroacide), meaning between the 15th of July and 1st of August.

\subsection{Flumethrin detection and residue concentration}

Beeswax was analysed for the presence of flumethrin residues by GRIPA test laboratory (Beaucouzé, France) according to the European NF EN 15662 method (CEN, 2008). Solubilisation was made with acetonitrile (ACN) before the addition of water and citrate salts ( sodium chloride, magnesium sulfate, sodium citrate and sodium hydrogenocitrate sesquihydrate) in order to separate $\mathrm{ACN}$ from water. The ACN extract was shaken and centrifuged to purify it with dispersive QuEChERS's salt (mix of MgSO4 and Primary and Secondary Amine). The final extract was directly used for LC-MS/MS. Quantification was performed using addition of flumethrin in blank beeswax extract before injection (calibration curve from $1 \mu \mathrm{g} / \mathrm{l}$ to $50 \mu \mathrm{g} / \mathrm{l}$ ). Samples with higher contents are diluted with ACN to integrate the linearity range. Flumethrin was also added before extraction (different level between $20 \mu \mathrm{g} / \mathrm{kg}$ and $100 \mu \mathrm{g} / \mathrm{kg}$ ) to another blank beeswax sample (each analysis batch) to

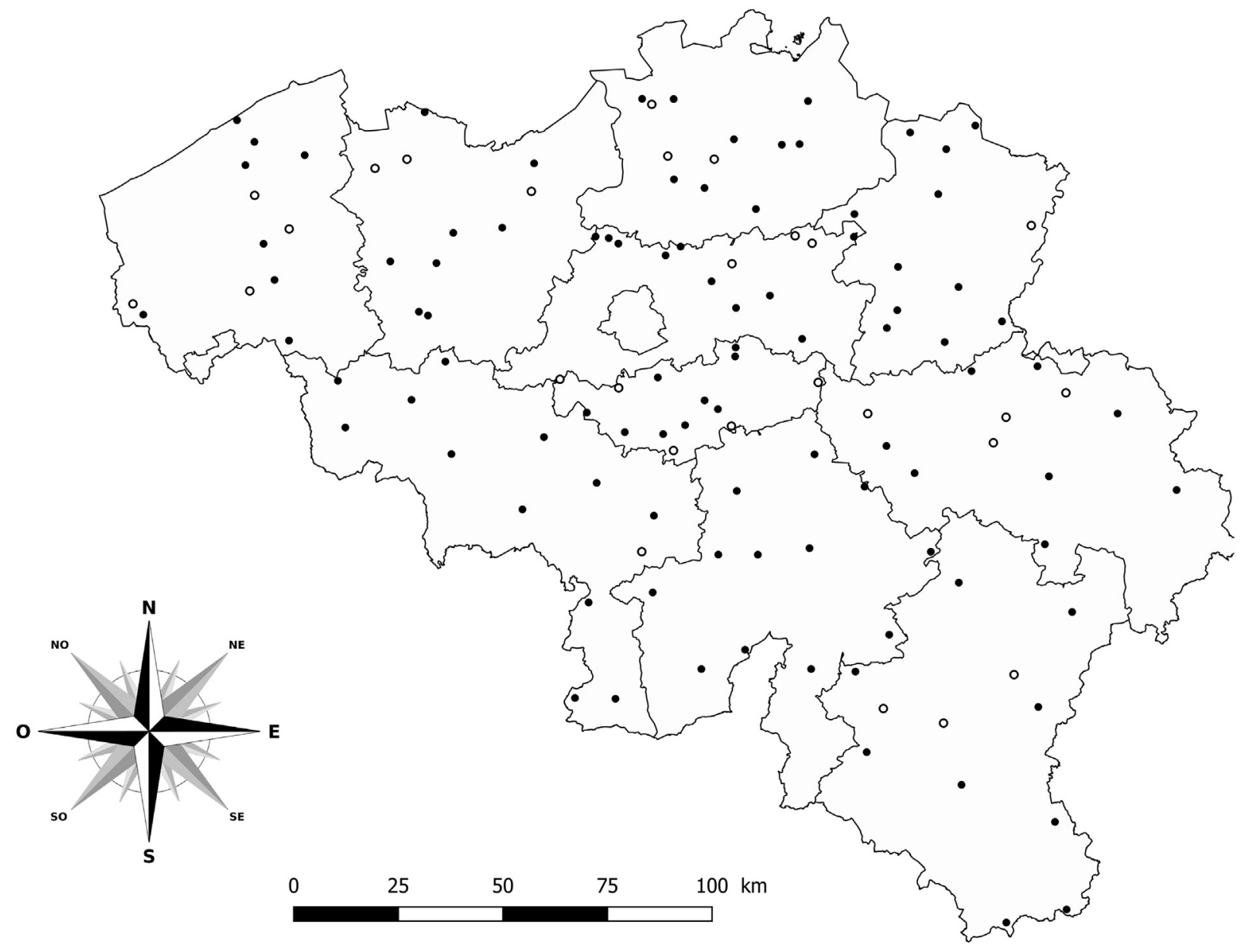

Fig. 1. negative sample for flumethrin; $\bigcirc$ positive sample for flumethrin. 
obtain recovery rate and the validation of the capacity to detect and quantitate with good accuracy the limit of quantification (LOQ) set to $20 \mu \mathrm{g} / \mathrm{kg}$. Mean recovery is $95 \%$ with a relative standard deviation of 13 .

Analysis in LC/MS/MS has been done on Sciex 5500 Qtrap with Shimadzu HPLC pump (LC 20XAD) and Synergi Hydro RP® column from Phenomenex. Two transitions were followed to ensure the specificity of the method in negative electrospray mode ( 508 give 481 and 510 give 483). The Multiple Reaction Monitoring ratio (MRM ratio) criteria was fixed at $30 \%$ to discriminate false positive. A signal to noise ratio under 10 is not acceptable for both transitions to measure calibration point.

\subsection{Data collection on colony loss}

A questionnaire was filled out together with the sampling in order to record the general colony losses. The percentage of losses per apiary is the difference between the number of colonies in April 2016 and in September 2015 divided by the number of colonies (including splits) in September 2016 and multiplied by one hundred (Clermont et al., 2014).

We took in consideration, within the population of interest, the apiary size. Apiaries with large numbers of colonies will have a greater influence on the total colony loss metric than the apiaries with only few colonies (Kulhanek et al., 2017).

General colony loss is the most accurate snapshot of losses in Belgian apiaries over a fixed period of time (end beekeeping season) giving us a precise figure of the proportion of all colonies that died in Belgium.

\subsection{Non-pondered and pondered wax hazard quotient}

The acute risk of flumethrin residues in beeswax to bees was assessed separately considering an oral or a contact exposure. Since residue concentrations are significantly higher in wax, and migration poorly understood in this matrix, only samples with a $\mathrm{HQ}_{\text {wax }}>5000$ are associated with an elevated risk to honeybees (Traynor et al., 2016). As no information was found on the amount of masticated beeswax by honeybees, the following scenario was used. The cell weight was estimated by the average weight of 4 wax samples ( $1 \mathrm{dm}^{2}$ each) from a body wax frame divided by the number of cells which were counted recto and verso $(n=800)$. In this condition, the estimated cell weight was in average $0.0232 \mathrm{~g}$ (S.D. $=0.0015 \mathrm{~g}$ ).

For a colony including $\pm 50,000$ bees and considering that $50 \%$ (or 25,000 ) of them are foragers, $20 \%$ (or 5000 ) of them develop the ability to produce wax during 7 days (Winston, 1987). Worker honeybees build 3 sheets $\left(34.6 \mathrm{~cm} \times 19.9 \mathrm{~cm}=6.88 \mathrm{dm}^{2}\right.$ each) of wax (initially $65 \mathrm{~g}$ per sheet) within a Simplex body in 2 days by stretching and incorporating newly produced wax (Winston, 1987). Once built, these 3 sheets consisting of 800 cells per $\mathrm{dm}^{2}$, each weighing $0.0232 \mathrm{~g}$ will bring the weight of the 3 build wax sheet to $383 \mathrm{~g}\left(6.88 \mathrm{dm}^{2} \times\right.$ $800 \times 0.0232 \mathrm{~g} \times 3=383 \mathrm{~g})$. This amount of beeswax corresponds to $0.0383 \mathrm{~g}$ of masticated wax per bee and by day ( $=383 \mathrm{~g} /(5000$ bees $\times 2$ days)).

The acute toxicity determines the inherent toxicity of flumethrin to bees in experimental conditions. Currently, typical risk assessments consider only acute toxicity of chemicals either by topical or oral exposure, measured 24 or 48 h after exposure (Sanchez-Bayo and Goka, 2014).

The result as a certain dose expressed in $\mu \mathrm{g} /$ bee is a parameter and does not express the hazard of the product in the field. For this reason, we calculated the Hazard Quotient (HQ) per bee and sample for the specific matrix beeswax using a similar method described by (Stoner et al., 2013) and for which the equations are the following:

$H Q_{\text {contact wax }}$ per bee $=\frac{\text { Residue concentration in } \mu \mathrm{g} / \mathrm{kg} \text { beeswax }}{L D_{50} \text { contact in } \mu \mathrm{g} \text { bee }^{-1}}$
$H Q_{\text {oral wax }}$ per bee $=\frac{\text { Residue concentration in } \mu \mathrm{g} / \mathrm{kg} \text { beeswax }}{L D_{50} \text { oral in } \mu \mathrm{g} \mathrm{bee}^{-1}}$

For contact and oral routes, this standard calculation per sample is not fully a measure of the risk of honeybees being exposed to flumethrin residues through the beeswax, because it does not indicate the probability of a hazard to occur. To estimate the risk of honeybees being affected by flumethrin residues contaminated beeswax, it is necessary to consider also the frequency of detection of these residues in this matrix in Belgium, because prevalence indicates the probability of exposure to the contaminant (Sanchez-Bayo and Goka, 2014). Prevalence rate is the percentage of positive samples per province or par region.

Therefore, a pondered HQ (PHQ) should incorporate this probability as follow:

$P H Q=H Q_{\text {contact wax }} \times$ prevalence rate $[\%]$
$P H Q=H Q_{\text {oral } w a x} \times$ prevalence rate $[\%]$

\subsection{Flumethrin residues estimated daily intake for Belgian consumers of} honey and beeswax

The estimated daily intake (EDI) of flumethrin residues by consumers through the consumption of honey and beeswax was assessed using both deterministic and probabilistic approaches. In the deterministic approach, the EDI was based on a worst-case scenario (EDI $\mathrm{WCS}_{\text {) }}$. The EDI ${ }_{\text {Wcs }}$ was calculated on the basis of the percentile 95 (P95) of flumethrin residues concentrations found in beeswax of Belgian hives multiplied respectively by the P95 of honey consumption (i.e. $50 \mathrm{~g}$ of honey per day and per person) and the P95 of the beeswax consumption (i.e. $1.29 \mathrm{~g}$ beeswax per day and per person) (Wilmart et al., 2016). In the probabilistic approach, both distributions of flumethrin residues concentrations and honey consumption were considered. For this approach, honey consumption data were extracted from the national human consumption survey performed in 2004 in Belgium (De Vriese et al., 2005). This consumption survey concerns adults older than 14 years of both sex ( $n=3083$ persons involved). In this approach, individual consumption and contamination data are converted into a distribution function (Table 1) and computed using @Risk software (version 7.5; Palisade Corporation, New York, NY, USA). Afterward, distribution functions are combined using a Monte Carlo simulation with 100,000 iterations to obtain a function of flumethrin EDI.

To our knowledge, very few studies exist about contaminations of honey by contaminated beeswax. The percentage of transfer depends on the lipophilicity of the active substance. The Log $P$ values or the logarithm of the ratio of the concentrations of flumethrin in the solvents octanol and water is of 6.2 (http://sitem.herts.ac.uk/aeru/vsdb/ Reports/1480.htm). Chemicals with low Log P values (e.g., $<1$ ) may be considered relatively hydrophilic; conversely, chemicals with high Log P values (e.g., >4) are very hydrophobic, in other words, highly lipophilic. Flumethrin is highly lipophilic ( $\log P$ of 6.2 ). This induces a very low transfer from beeswax to honey. A previous study that aimed to determine the limit after which the concentration of active

Table 1

List of the distributions used for the probabilistic risk assessment (only "consuming" people are presented) according to the @Risk software notations.

\begin{tabular}{ll}
\hline Parameter & Distribution function in @Risk \\
\hline Flumethrin contamination & \\
Lower bound approach & RiskExpon $(0,014919 ;$ RiskShift $(0))$ \\
Middel bound approach & RiskPareto $(2,7117 ; 0,01)$ \\
Upper bound approach & RiskPareto $(4,5905 ; 0,02)$ \\
Honey consumption & RiskLognorm $(15,277 ; 19,221 ;$ RiskShift $(0,77739))$ \\
\hline Legend: P95, percentile 95 &
\end{tabular}


varroacide constituents in the frame wax move and become quantitatively detectable in honey, with a detection threshold for flumethrin residues of $5 \mu \mathrm{g} / \mathrm{kg}$, showed that there was no detectable transfer of flumethrin residues from wax into honey, in experimental conditions (Wallner, 1992).

For this reason, we consider only $1 \%$ of flumethrin residues migrating to honey. Considering that a frame completely filled with honey contained approximately $1.84 \mathrm{~kg}$ of honey (Simplex standard frame), the wax/honey ratio is $128 / 1840 \mathrm{~g}=0.069$ (Reybroeck et al., 2010).

The EDI of flumethrin residues by the consumer is:

$E D I_{\text {wax }}=B D C$ per person $X$ beeswax contamination

which, BDC is the beeswax daily consumption.

$E D C_{\text {honey }}=H D C$ per person $X$ beeswax contamination $X 0.069 X 0.01(6$

which, HDC is the honey daily consumption, 0.069 the wax/honey ratio and 0.01 the maximum transfer from beeswax to honey.

\subsection{Statistical analysis}

Comparison between prevalence rates and flumethrin residues concentrations between regions were respectively assessed using a Chi2 and a Mann-Whitney $U$ test. The relation between the average flumethrin residues concentrations and the colony losses was tested using both the Pearson correlation coefficient and Spearman rank correlation coefficient. The average of flumethrin residues concentrations between groups of colonies with loss lower and equal or higher than $10 \%$ was tested using Two-sample $t$-test with unequal variances. In addition, a negative binomial regression was used to investigate the relation between both contact and oral pondered hazard quotient. In this analysis, the number of colony losses was weighted by the size of apiary as exposure. All statistical analyses were carried out in STATA/SE 14.2 (StataCorp, College Station, TX, USA). The limit of statistical significance of the tests performed was defined as 0.05 .

\section{Results/discussion}

\subsection{Flumethrin detection and concentration in positive beeswax samples}

Out of the 124 analysed beeswax samples (61 from Flanders and 63 from Wallonia), 27 samples were found with flumethrin residues (14 from Flanders and 13 from Wallonia) (Table 2). Unexpectedly, the Belgian mean prevalence rate was of $21.77 \%$ (95\% CI: 14.87-30.08) with no significant difference in prevalence rates between Flanders and
Wallonia (Chi2 ${ }_{(\alpha=0.05 ;} 1$ d.d.l.) $\left.=0.10 ; P=0.76\right)$, showing that flumethrin use in Belgium is quite widespread at the national level even if the substance was only authorised under veterinary prescription before February 2017, in the case of the "cascade system”. The Belgian average flumethrin residues concentration for contaminated beeswax samples was $68.52 \mu \mathrm{g} / \mathrm{kg}$ with a standard deviation of $58.2 \mu \mathrm{g} / \mathrm{kg}$ ( median $=48 \mu \mathrm{g} / \mathrm{kg} ;$ min $=21 \mu \mathrm{g} / \mathrm{kg}$ and $\max =280 \mu \mathrm{g} / \mathrm{kg}$ ) with no significant difference in the flumethrin residues concentration between regions (Mann-Whitney $U$ test; $P=0.08$ ). The highest concentrations were observed for samples from provinces of Antwerp $(280 \mu \mathrm{g} / \mathrm{kg})$ and of Walloon Brabant (190 $\mu \mathrm{g} / \mathrm{kg}$ ) (Table 2). As for prevalence rates, no significant difference in flumethrin residues concentrations was found between both regions.

Surprisingly, no beekeeper indicated using this substance for varroosis treatment in the associated face-to-face questionnaire (El Agrebi, personal communication). The origin of the contamination could provide from historic use of flumethrin by the beekeepers (previous years) or from flumethrin residues contaminated trade beeswax before it use by the beekeepers as flumethrin shows high lipophilic properties ( $\log P=6.2$ ) (Lewis et al., 2016) and remains in beeswax.

In a study on the prevalence of pesticides residues in beeswax in Spain (Calatayud-Vernich et al., 2017), the flumethrin residues mean concentration found was of $90.5 \mu \mathrm{g} / \mathrm{kg}$ (min-max; 48-170.1 $\mu \mathrm{g} / \mathrm{kg}$ ). Nevertheless, the limit of quantification (LOQ) for flumethrin in the Spanish study was lower $(12.5 \mu \mathrm{g} / \mathrm{kg})$ than in the present study (20 $\mu \mathrm{g} / \mathrm{kg}$ ). The prevalence rate in Spain was of $81.8 \%$ (Calatayud-Vernich et al., 2017).

\subsection{Non-pondered and pondered wax hazard quotient}

The exposure of honeybees to pesticides residues involves both contact and oral routes (Alix and Vergnet, 2007). For both exposure routes, the non-pondered $H Q_{\text {wax }}$ is compared with a trigger value of 50 (Alix and Vergnet, 2007) considered as a risk to adult worker honeybees. Nevertheless, since residues concentrations can be significantly higher in wax, and transmission routes poorly understood in this matrix, only values of contact $H Q_{w a x}>5000$ correspond to an elevated risk to honeybees (Traynor et al., 2016). Contact non-pondered hazard quotient ranged from 420 to 5600 with a mean value of 1370 (S.D. $=1164$ ) and 1 out of 27 beeswax samples was associated with an elevated risk to honeybee health with a value of 5600. Oral non-pondered hazard quotient ranged from 118 to 1573 with a mean value of 385 (S.D. = 327). When the flumethrin residues prevalence rates were considered (PHQ) the mean contact PHQ decrease up to 384 (S.D. = 333; min$\max =51-1292$ ) and the mean oral PHQ decrease up to 108 (S.D. $=$ 94 ; min-max $=14-363$ ) (Table 2 ) but remained above the trigger

Table 2

Prevalence rate and concentration of flumethrin residues $(\mu \mathrm{g} / \mathrm{kg})$ in beeswax samples from the two Belgian regions and calculated oral/contact HQ/PHQ for each province.

\begin{tabular}{|c|c|c|c|c|c|c|c|c|c|c|c|}
\hline \multirow[b]{2}{*}{ Area } & \multirow[b]{2}{*}{$\mathrm{Np}$} & \multirow[b]{2}{*}{$\mathrm{Nn}$} & \multirow[b]{2}{*}{ Prevalence rate (\%) } & \multicolumn{4}{|c|}{ Concentration $(\mu \mathrm{g} / \mathrm{kg})$ in $\mathrm{Np}$} & \multirow{2}{*}{$\begin{array}{l}\text { HQ } \\
\text { Contact }\end{array}$} & \multirow[b]{2}{*}{ Oral } & \multirow{2}{*}{$\frac{\text { PHQ }}{\text { Contact }}$} & \multirow[b]{2}{*}{ Oral } \\
\hline & & & & Min & Max & Average & Median & & & & \\
\hline Antwerp & 3 & 10 & $23.08 \%$ & 29 & 280 & 143 & 120 & 2860 & 803 & 660 & 185 \\
\hline Limburg & 1 & 11 & $8.33 \%$ & 31 & 31 & 31 & NA & 620 & 174 & 51 & 14 \\
\hline East Flanders & 3 & 9 & $25 \%$ & 26 & 40 & 35 & 40 & 707 & 199 & 177 & 50 \\
\hline Flemish Brabant & 3 & 9 & $25 \%$ & 54 & 59 & 57 & 58 & 1140 & 320 & 285 & 81 \\
\hline West Flanders & 4 & 8 & $33.33 \%$ & 21 & 50 & 32 & 29 & 645 & 181 & 215 & 60 \\
\hline Flanders & 14 & 47 & $22.95 \%$ & 21 & 280 & 62 & 40 & 1237 & 348 & 348 & 86 \\
\hline Wallon Brabant & 5 & 9 & $35.71 \%$ & 54 & 190 & 104 & 94 & 2084 & 585 & 694 & 195 \\
\hline Hainaut & 1 & 12 & $7.69 \%$ & 46 & 46 & 46 & NA & 920 & 258 & 64 & 18 \\
\hline Liège & 4 & 8 & $33.33 \%$ & 32 & 140 & 72 & 58 & 1435 & 403 & 478 & 134 \\
\hline Luxemburg & 3 & 9 & $25 \%$ & 41 & 48 & 43 & 41 & 867 & 243 & 217 & 61 \\
\hline Namur & 0 & 12 & $0 \%$ & NA & NA & NA & NA & NA & NA & NA & NA \\
\hline Wallonia & 13 & 50 & $20.63 \%$ & 32 & 190 & 76 & 54 & 1514 & 425 & 425 & 132 \\
\hline Belgium & 27 & 97 & $21.77 \%$ & 21 & 280 & 69 & 48 & 1370 & 385 & 385 & 108 \\
\hline
\end{tabular}

Legend: Np, number of positive; Nn, number of negative; HQ hazard quotient; PHQ pondered hazard quotient; NA, non-applicable. 
value of 50 and represents thus a risk to bees. At best, the HQ provides an underestimate of total exposure and does not take into account flumethrin cumulative and sub-lethal effects on the colony. Because of the specific toxicokinetic profile of honeybees compared with other insects, it is recognised that toxicokinetic data can provide useful information on the potential biological persistence of a pesticide residue which, in some cases, could have effects after continuous exposure that maybe more marked compared with their short-term effects (EFSA, 2013). Unfortunately, the current state of knowledge does not permit the development of more robust models that include these factors, and thus we used this more simplistic model as a point of departure to help understand the risk posed by the real world exposure experienced by honeybee colonies (Traynor et al., 2016). More precise calculation would use the $\mathrm{LD}_{10}$ instead of $\mathrm{LD}_{50}$ 's or the same but for chronic toxicity, however this toxicological reference dose is currently not available for flumethrin (Traynor et al., 2016).

\subsection{Flumethrin residues concentrations and pondered hazard quotients compared to colony loss}

We found no linear (Pearson correlation coefficient $=-0,22 ; P=$ 0.55 ) and no non-parametric (Spearman rank correlation coefficient $=0.13 ; P=0.73$ ) relation between average flumethrin residues concentrations expressed in $\mu \mathrm{g} / \mathrm{kg}$ compared to average mortalities expressed in percent per province in Belgium (Fig. 2). There is no significant difference concerning the average flumethrin residues concentrations between apiaries with lower and equal or higher than $10 \%$ of colony loss (Two-sample $t$-test with unequal variances; $P=0.60$ ).

There is no significant difference concerning the contact (negative binomial regression; $P=0.537$ ) and oral (negative binomial regression; $P=0.535$ ) pondered hazard quotients between apiaries with less and equal or higher than $10 \%$ of colony loss.

In this study, we only focused on flumethrin residues contaminations and their possible direct impact on honeybee mortality. Till today, no specific causal agent has yet been identified, but there is a wide consensus on the multifactorial origin of colony losses that are often associated with high infection levels of parasites and/or pathogens (Neumann and Carreck, 2015; Ratnieks and Carreck, 2010). There is no consensus either, regarding the relative importance of these factors, singly or in combination (Van Engelsdorp and Meixner, 2010). We can't thus identify flumethrin residues in beeswax as a risk factor of bee mortality alone, but it could be one in combination with other pesticides like fungicides (Thompson, 2012).
3.4. Belgian honey and/or beeswax consumer's flumethrin residues estimated daily intake

The EDI of flumethrin residues by consumers through the consumption of honey and beeswax was estimated with both determinist and probabilistic approaches. In the determinist approach, only the EDI in a worst-case scenario (P95 for wax flumethrin residues concentration and for consumption data) (EDI wcs ) was considered. For the flumethrin concentration conversion from wax to honey, we have considered a wax/honey ratio of 0.069 and only $1 \%$ of flumethrin residues migrating from wax to honey due to the high lipophilicity (high Log P) of flumethrin. In the probabilistic approach, due to the absence of information on individual consumption of beeswax, the exposure assessment could only be performed for honey.

\subsubsection{Deterministic approach}

In the worst-case scenario, the flumethrin residues estimated daily intake through beeswax consumption $\left(E D I_{w c s-w a x}\right)$ is of $0.0955 \mu \mathrm{g}$ per day and per person (Eq. (5)). Flumethrin residues EDI in honey $\left(E D I_{\text {wcs-honey }}\right)$ is of $0.00256 \mu \mathrm{g}$ per day and per person (Eq. (6)) (Table 3 ). Both values represent $<0.1 \%$ of the TMDI.

As no randomness is involved in this model, the result of it can be validated nevertheless the multiplication of prudent assessment factors which may result in an overestimated overall result and therefore unrealistic reference values.

\subsubsection{Probabilistic approach}

Considering the lower (for each value below the LOQ 0 was attributed), the middle (for each value below the LOQ value of LOQ/2 was attributed) and the upper (for each value below the LOQ, value of LOQ was attributed) bound approaches, the mean $\mathrm{EDI}_{\text {honey }}$ was respectively $0.00013,0.00014$ and $0.00072 \mu \mathrm{g}$ flumethrin per day and per person. In the same way, the P95 $\mathrm{EDI}_{\text {honey }}$ was respectively $0.0004,0.0004$ and $0.00069 \mu$ flumethrin per day and per person. In all the previous cases, the mean $\mathrm{EDI}_{\text {honey }}$ represents $<0.0002 \%$ of the TMDI. When we consider the maximum values of the $\mathrm{EDI}_{\text {honey }}$ in each approach, the maximum percentage of the TMDI was $<0.007 \%$. The probabilistic approach was not possible for beeswax consumption due to the lack of individual consumption data.

This approach intends to describe more clearly variability and/or uncertainties in yielding quantitative insight into both the possible range and the relative likelihood of values for model outputs. According to both approaches, flumethrin residues in beeswax and in honey do not pose a risk to human health (= calculated EDI values very much

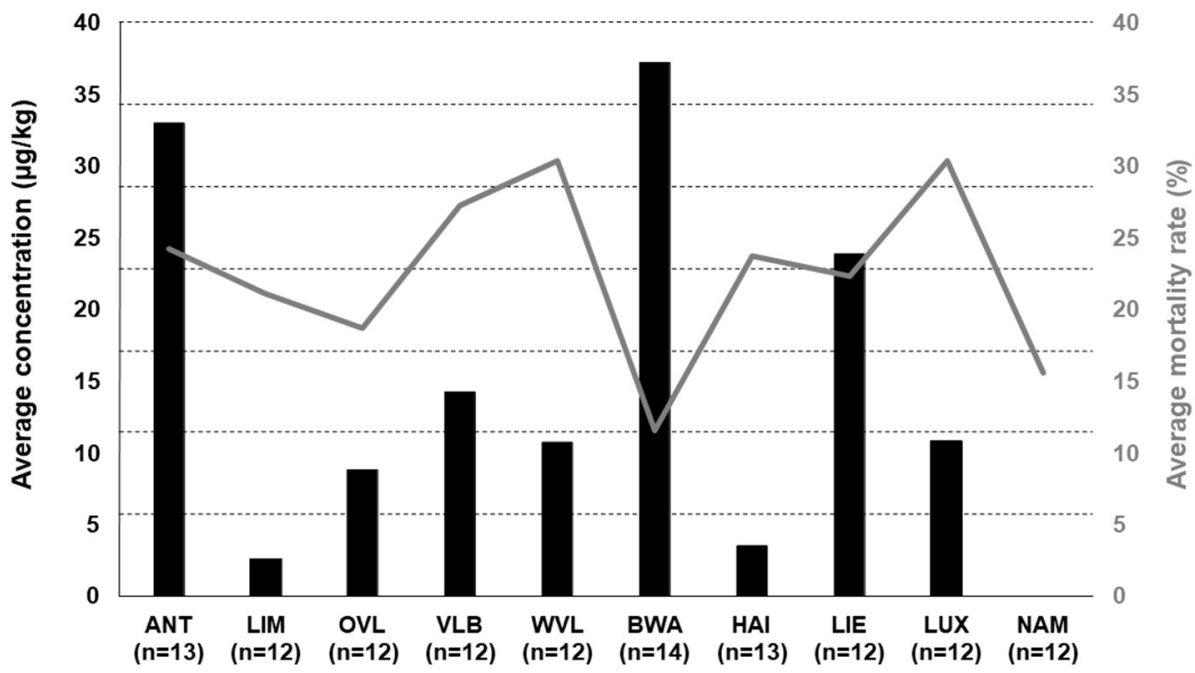

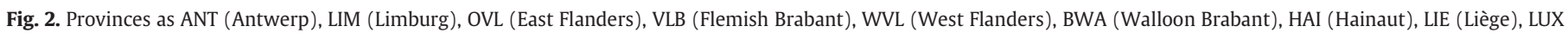
(Luxembourg), NAM (Namur). 
Table 3

Deterministic calculation of the estimated daily intake in the worst-case scenario* for honey and/or beeswax consumers only expressed in percentage of the TMDI.

\begin{tabular}{lcc}
\hline Parameter & \multicolumn{2}{l}{ Consumption } \\
\cline { 2 - 3 } & Honey & Wax \\
\hline Flumethrin residue concentration in wax $(\mathrm{mg} / \mathrm{kg})$ & - & 0.07405 \\
Flumethrin residue concentration in wax $(\mu \mathrm{g} / \mathrm{kg})$ & - & 74.05 \\
Flumethrin residue concentration in honey $(\mu \mathrm{g} / \mathrm{kg})$ & 0.05109 & - \\
$\quad$ considering the wax/honey ratio $(0,069)$ and the & & \\
$\quad$ coefficient of migration $(0.01)$ & 50 & 1.29 \\
Consumed quantity ( $\mathrm{g}$ per day and person) & 0.05 & 0.00129 \\
Consumed quantity (kg per day and person) & 60 & 60 \\
Body weight $(\mathrm{kg})$ & 0.00004258 & 0.00159208 \\
EDI ( $\mu$ g per day and per kg of body weight) & $0 . ; 002555$ & 0.0955245 \\
EDI ( $\mu$ g per day and per person of 60 kg) & 108 & 108 \\
TMDI ( $\mu$ g per day and per person of 60 kg) & 0.0024 & 0.0885 \\
\% of TMDI & & \\
\hline
\end{tabular}

Legend: *Percentile 95 (P95) of the flumethrin residue concentration and P95 of the honey consumption.

lower than the ADI). This is mainly due to the low level of beeswax consumption and to the low level of flumethrin residues in honey. Nevertheless, other foodstuffs can contribute to the consumers' exposure to flumethrin residues (EMEA, 1998; Wilmart et al., 2016).

\section{Conclusions}

The results of this study highlight the importance of considering the risk of pesticides both for honeybee health and for human health perspectives. Flumethrin residues in beeswax and in honey do not appear to pose a risk to human health but represent a risk to honeybee health. The benefit of the flumethrin use should be considered in regard to its toxic effects on bees. In order to decrease the level of pesticide residues in beeswax, we recommend to (i) inform beekeepers about flumethrin risks (HQ and PHQ) to honeybee health and to its correct use, (ii) replace the old frames from the brood chamber by low residue beeswax foundation in order to ensure a complete frame turnover in the hive after 2 to 3 years. The exclusion of honey and beeswax frames that are in contact with the strips could also lead to a drastic reduction of residual flumethrin concentrations in the final product.

\section{Acknowledgment}

We gratefully acknowledge the Federal Agency for the Safety of the Food Chain (FASFC) for the financial support in the chemical analysis and interest in the study. The authors wish to thank the Belgian beekeepers for their participation in this study and for allowing us to use their beeswax. Thanks also to the GIRPA Test Laboratory (Beaucouzé, France) for the chemical analyses and to Dr. Laurent Delooz for the map.

\section{Funding sources}

Federal Agency for the Safety of the Food Chain (FASFC).

\section{References}

Aizen, M.A., Garibaldi, L.A., Cunningham, S.A., Klein, A.M., 2009. How much does agriculture depend on pollinators? Lessons from long-term trends in crop production. Ann. Bot. 103, 1579-1588. https://doi.org/10.1093/aob/mcp076.

Alix, A., Vergnet, C., 2007. Risk assessment to honey bees: a scheme developed in France for non-sprayed systemic compounds. Pest Manag. Sci. 63, 1069-1080. https://doi. org/10.1002/ps.1463.

Balbuena, Tison, L., Hahn, M.-L., Greggers, U., Menzel, R., Farina, W.M., 2015. Effects of sublethal doses of glyphosate on honeybee navigation. J. Exp. Biol. 218, 2799-2805. https://doi.org/10.1242/jeb.117291.

Benuszak, J., Laurent, M., Chauzat, M.-P., 2017. The exposure of honey bees (Apis mellifera; Hymenoptera: Apidae) to pesticides: room for improvement in research. Sci. Total Environ. 587-588, 423-438. https://doi.org/10.1016/j. scitotenv.2017.02.062
Calatayud-Vernich, P., Calatayud, F., Simó, E., Picó, Y., 2017. Occurrence of pesticide residues in Spanish beeswax. Sci. Total Environ. 605-606, 745-754. https://doi.org/ 10.1016/J.SCITOTENV.2017.06.174.

CEN, 2008. Foods of Plant Origin - Determination of Pesticide Residues Using GC-MS and or LC-MS/MS Following Acetonitrile Extraction/Partitioning and Cleanup by Dispersive SPE-QuEChERS-method.

Chauzat, M.-P., Faucon, J.-P., 2007. Pesticide residues in beeswax samples collected from honey bee colonies (Apis mellifera L.) in France. Pest Manag. Sci. 63, 1100-1106. https://doi.org/10.1002/ps.1451.

Chauzat, M.-P., Carpentier, P., Martel, A.-C., Bougeard, S.P., Cougoule, N., Porta, P., Lachaize, J., Madec, F.O., Aubert, M., Faucon, J.-P., Bougeard, S.P., Madec, F.O., 2009. Influence of pesticide residues on honey bee (hymenoptera: Apidae) Colony health in France. Environ. Entomol. 38, 514-523. https://doi.org/10.1603/022.038.0302.

Clermont, A., Eickermann, M., Kraus, F., Georges, C., Hoffmann, L., Beyer, M., 2014. A survey on some factors potentially affecting losses of managed honey bee colonies in Luxembourg over the winters 2010/2011 and 2011/2012. J. Apic. Res. 53, 43-56. https://doi.org/10.3896/IBRA.1.53.1.04.

De Vriese, S., De Backer, G., De Henauw, S., Huybrechts, I., Kornitzer, K., Leveque, A., Moreau, M., Van Oyen, H., 2005. The Belgian food consumption survey: aims, design and methods by. Public Health 1-16.

EFSA, 2007. Beeswax (E 901) as a glazing agent and as carrier for flavours scientific opinion of the panel on food additives, flavourings, processing aids and materials in contact with food (AFC). EFSA J. 615, 1-28.

EFSA, 2012. Scientific opinion on the science behind the development of a risk assessment of plant protection products on bees (Apis mellifera, Bombus spp. and solitary bees). EFSA J. 10, 2668. https://doi.org/10.2903/j.efsa.2012.2668.

EFSA, 2013. Guidance on the risk assessment of plant protection products on bees (Apis mellifera, Bombus spp. and solitary bees). EFSA J. 11, 3295. https://doi.org/10.2903/ j.efsa.2013.3295.Available.

EMEA, 1998. Commitee for Veterinary Medecinal Products: Flumethrin Summery Report (1).

EU, 2002. EU. European Directive 2001/82/EC of the European Parliament and of the Council of 6 November 2001 on the Community Code Relating to Veterinary Medicinal Products.

EU Commission, 2018. Technical Guidelines for Determining the Magnitude of Pesticide Residues in Honey and Setting Maximum Residue Levels in Honey (SANTE/11956/ 2016 Rev. 9).

Fontaine, C., Dajoz, I., Meriguet, J., Loreau, M., 2005. Functional diversity of plantpollinator interaction webs enhances the persistence of plant communities. PLoS Biol. 4, e1. https://doi.org/10.1371/journal.pbio.0040001.

Garibaldi, L.A., Steffan-dewenter, I., Winfree, R., Aizen, M.A., Bommarco, R., Cunningham, S.A., Kremen, C., Carvalheiro, L.G., 2014. Wild pollinators enhance fruit set of crops regardless of honey bee abundance. Science (80-. ) 339, 1608-1611. https://doi.org/ 10.1126/science. 1230200 .

Hardstone, M.C., Scott, J.G., 2010. Is Apis mellifera more sensitive to insecticides than other insects? Pest Manag. Sci. 66, 1171-1180. https://doi.org/10.1002/ps.2001.

Hesketh, H., Lahive, E., Horton, A.A., Robinson, A.G., Svendsen, C., Rortais, A., Dorne, J.-L., Baas, J., Spurgeon, D.J., Heard, M.S., 2016. Extending standard testing period in honeybees to predict lifespan impacts of pesticides and heavy metals using dynamic energy budget modelling. Sci. Rep. 6, 37655. https://doi.org/10.1038/srep37655.

Johnson, R., Dahlgren, L., Siegfried, B., Ellis, M., 2013. Effect of in-hive miticides on drone honey bee survival and sperm viability. J. Apic. Res. 52, 88-95. https://doi.org/ 10.3896/IBRA.1.52.2.18.

Johnson, R.M., 2014. Honey bee toxicology. Annu. Rev. Entomol. 60, 415-434. https://doi. org/10.1146/annurev-ento-011613-162005.

Karazafiris, E., Tananaki, C., Thrasyvoulou, A., Menkissoglu-Spiroudi, U., 2012. Pesticide residues in bee products. Pestic. Mod. World - Risks Benefits https://doi.org/ $10.5772 / 19409$.

Klein, A.-M., Vaissière, B.E., Cane, J.H., Steffan-Dewenter, I., Cunningham, S.A., Kremen, C. Tscharntke, T., 2007. Importance of pollinators in changing landscapes for world crops. Proc. Biol. Sci. 274, 303-313. https://doi.org/10.1098/rspb.2006.3721.

Kulhanek, K., Steinhauer, N., Rennich, K., Caron, D.M., Sagili, R.R., Pettis, J.S., Ellis, J.D. Wilson, M.E., Wilkes, J.T., Tarpy, D.R., Rose, R., Lee, K., Rangel, J., VanEngelsdorp D., 2017. A national survey of managed honey bee 2015-2016 annual colony losses in the USA. J. Apic. Res. 56, 328-340. https://doi.org/10.1080/ 00218839.2017.1344496.

Lewis, K.A., Tzilivakis, J., Warner, D.J., Green, A., 2016. An international database for pesticide risk assessments and management. Hum. Ecol. Risk. Assess. 22, 1050-1064. https://doi.org/10.1080/10807039.2015.1133242.

Lozano, A., Hernando, M.D., Uclés, S., Hakme, E., Fernández-Alba, A.R., 2019. Identification and measurement of veterinary drug residues in beehive products. Food Chem. 274 61-70. https://doi.org/10.1016/J.FOODCHEM.2018.08.055.

Neumann \& Carreck, 2015. Honey bee colony losses. J. Apic. Res. 49 (1), 1-6.

OECD, 2013. Test No. 237: Honey Bee (Apis mellifera) Larval Toxicity Test, Single Exposure. https://doi.org/10.1787/9789264203723-en.

OECD, 2018. Honey bee (Apis mellifera L.), chronic oral toxicity test 245 (10-day feeding). Guidel. Test. Chem., 1-7 https://doi.org/10.1787/9789264070820-en.

Oruc, H.H., Hranitz, J.M., Sorucu, a., Duell, M., Cakmak, I., Aydin, L., Orman, a., 2012. Determination of acute Oral toxicity of flumethrin in honey bees. J. Econ. Entomol. 105, 1890-1894. https://doi.org/10.1603/EC12055.

Patel, M., Patil, P., 2016. Synthetic Pyrethroids: toxicity and metabolism. J. Agric. Vet. Sci. 09, 55-60. https://doi.org/10.9790/2380-0910015560.

Perez Santiago, G., Otero-Colina, G., Mota Sanchez, D., Ramirez Guzman, M.E., Vandame R., 2000. Comparing effects of three acaricides on Varroa jacobsoni (Acari: Varroidae) and Apis mellifera (Hymenoptera: Apidae) using two application techniques. Fla. Entomol. 83, 468-476. https://doi.org/10.2307/3496722. 
Pettis, J.S., vanEngelsdorp, D., Johnson, J., Dively, G., 2012. Pesticide exposure in honey bees results in increased levels of the gut pathogen Nosema. Naturwissenschaften 99, 153-158. https://doi.org/10.1007/s00114-011-0881-1.

Potts, S.G., Biesmeijer, J.C., Kremen, C., Neumann, P., Schweiger, O., Kunin, W.E., 2010. Global pollinator declines: trends, impacts and drivers. Trends Ecol. Evol. 25, 345-353. https://doi.org/10.1016/j.tree.2010.01.007.

Ratnieks, F.L.W., Carreck, N.L., 2010. Ecology. Clarity on honey bee collapse? Science 327, 152-153. https://doi.org/10.1126/science.1185563.

Ravoet, J., Reybroeck, W., de Graaf, D.C., 2015. Pesticides for apicultural and/or agricultural application found in Belgian honey bee wax combs. Bull. Environ. Contam. Toxicol. 94, 543-548. https://doi.org/10.1007/s00128-015-1511-y.

Reybroeck, W., Jacobs, F.J., De Brabander, H.F., Daeseleire, E., 2010. Transfer of sulfamethazine from contaminated beeswax to honey. J. Agric. Food Chem. 58, 7258-7265 https://doi.org/10.1021/jf1005275.

Rumkee, J.C.O. Becher, M.A. Thorbek, P. Kennedy, PJ, Osborne, J.L. 2015. Predicting honeybee colony failure: using the BEEHAVE model to simulate colony responses to pesticides. Environ. Sci. Technol. 49, 12879-12887. https://doi.org/10.1021/acs. est.5b03593.

Sanchez-Bayo, F., Goka, K., 2014. Pesticide residues and bees - a risk assessment. PLoS One 9, e94482. https://doi.org/10.1371/journal.pone.0094482.

Stoner, K.A., Eitzer, B.D., Pacini, E., Roe, R., Lambin, M., 2013. Using a Hazard quotient to evaluate pesticide residues detected in pollen trapped from honey bees (Apis mellifera) in Connecticut. PLoS One 8, 1-10. https://doi.org/10.1371/journal. pone.0077550.

Thompson, H.M., 2012. Interaction between pesticides and other factors in effects on bees. Fera Report.

Tlak Gajger, I., Kosanović, M., Bilandžić, N., Sedak, M., Čalopek, B., 2016. Variations in lead, cadmium, arsenic, and mercury concentrations during honeybee wax processing using casting technology. Arch. Ind. Hyg. Toxicol. 67, 223-228. https://doi.org/ 10.1515/aiht-2016-67-2780.

Traynor, K.S., Pettis, J.S., Tarpy, D.R., Mullin, C.A., Frazier, J.L., Frazier, M., vanEngelsdorp, D., 2016. In-hive pesticide Exposome: assessing risks to migratory honey bees from inhive pesticide contamination in the eastern United States. Sci. Rep. 6, 33207. https://doi.org/10.1038/srep33207.

Tremolada, P., Vighi, M., 2014. Mathematical models for the comprehension of chemical contamination into the hive. In Silico Bees. CRC Press, London.

Van Engelsdorp, D., Meixner, M.D., 2010. A historical review of managed honey bee populations in Europe and the United States and the factors that may affect them. J. Invertebr. Pathol. 103, 80-95. https://doi.org/10.1016/j.jip.2009.06.011.

van Engelsdorp, D., Lengerich, E., Spleen, A., Dainat, B., Cresswell, J., Baylis, K., Nguyen, K.B. Soroker, V., Underwood, R., Human, H., Le Conte, Y., Saegerman, C., 2013. Standard epidemiological methods to understand and improve Apis mellifera health. J. Apic. Res. 52, 1-16. https://doi.org/10.3896/IBRA.1.52.1.08.

Wallner, K., 1992. Diffusion varroazider Wirkstoffe aus dem Wachs in den Honig. Apidologie 23, 387-389.

Wallner, K., 1999. Varroacides and their residues in bee products. Apidologie 30, 235-248.

Wilmart, O., Legrève, A., Scippo, M.-L., Reybroeck, W., Urbain, B., de Graaf, D.C., Steurbaut, W., Delahaut, P., Gustin, P., Nguyen, B.K., Saegerman, C., 2016. Residues in beeswax: a health risk for the consumer of honey and beeswax? J. Agric. Food Chem. 64, 8425-8434. https://doi.org/10.1021/acs.jafc.6b02813.

Winston, M.L., 1987. The Biology of the Honey Bee. Harvard University Press https://doi. org/10.1086/415773. 